\title{
Perancangan Sistem Pendukung Keputusan Penentuan Ketua Osis Dengan Menerapkan Metode Composite Performance Index (Cpi) (Studi Kasus : Smp Swasta Kavri Talun Kenas)
}

\section{Article Info}

Article history:

Received 28 February, 2021

Revised 27 March, 2021

Accepted 01 April, 2021

Keywords:

Student council, Decision Support System, Composite Performance Index

\begin{abstract}
Decision support system is part of a computer-based information system that can be used to support decision making in an organization or company. Decision support systems can be generated using several methods, one of which is the Composite Performance Index (CPI) method. Composite Performance Index is a composite Index that can be used to determine the determination or ranking of various alternatives based on several criteria. Intra-School Student Organizations (OSIS) have a special function in preparing students to implement management systems and leadership.In determining the student council chairman has criteria, such as intelligence, behavior,craftsmanship, and neatness, which usually the school still records manually so that it is considered less effective.
\end{abstract}

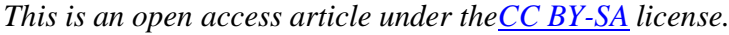

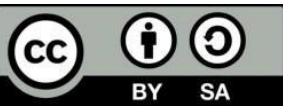

\section{Corresponding Author:}

Suci Ananda Tarigan

STMIK Budi Darma Medan, Informatics Management, Medan, Indonesia

Email Address: tar19an@gmail.com

(C) 2021 The Author: Published by. Cattleya Darmaya Fortuna

\section{Pendahuluan}

Organisasi Siswa Intra Sekolah (OSIS) merupakan salah satu sarana pengembangan minat dan bakat siswa di internal sekolah. Eksistensi OSIS ini dapat bermanfaat untuk sekolah dan masyarakat. OSIS juga merupakan komponen utama dari sekolah yang menjadi pioneer untuk perkembangan yang ada di sekolah [1]. Dalam kegiatan sekolah yang wajib dilakukan setiap tahun yaitu pemilihan ketua OSIS yang dilakukan dengan memberi penilaian terhadap siswa. Penilaian tersebut dilakukan untuk mengetahui peringkat siswa untuk dapat menjadi ketua OSIS karena OSIS menjadi salah satu organisasi yang sering diberi tanggung jawab oleh pihak sekolah untuk merencanakan kegiatan. Dalam proses pemilihan ketua osis saat ini masih kurang efektif dikarenakan masih secara konvensional [2] dengan menggunakan media penyampaian informasi yang sederhana yaitu berupa hanya lembaran kertas untuk memilih calon sehingga masih belum maksimal [3], sehingga akan memerlukan biaya yang besar dan waktu yang cukup lama untuk mengetahui hasilnya [4]. Berdasar pada 
permasalahan tersebut maka diperlukan metode tertentu untuk mendapatkan rekomendasi ketua OSIS yang sesuai dengan kriteria yang diharapkan [5]. Sistem pendukung keputusan merupakan suatu sistem yang mampu memecahkan masalah secara efesian, efektif, yang bertujuan untuk membantu pengambilan keputusan dengan memilih berbagai alternatif keputusan [6]. Sistem pendukung keputusan memberikan suatu keputusan yang bersifat semiterstruktur, dimana tidak seorangpun tahu secara pasti bagaimana keputusan seharusnya dibuat [7]. SPK bertujuan untuk menyediakan informasi, membimbing, memberikan prediksi serta mengarahkan kepada pengguna informasi agar dapat melakukan pengambilan keputusan dengan lebih baik [8]. Sistem pendukung keputusan tidak dimaksudkan untuk menggantikan peran pengambil keputusan, tapi untuk membantu dan mendukung pengambil keputusan [9]. Berdasarkan pengujian yang dilakukan, sistem yang dibuat mampu memberikan hasil yang baik sesuai dengan perhitungan yang digunakan, membantu mempercepat dalam mengambil keputusan [10]. Sistem Pendukung Keputusan pemilihan calon ketua osis merupakan aplikasi yang didalamnya terdapat proses memilih siswa yang dapat menjadi calon ketua osis [11]. Subjek penelitian ini adalah Pembina OSIS, peserta didik pengurus OSIS dan Peserta didik bukan pengurus OSIS [12]. Sistem ini dibangun dengan menggunakan metode Composite Performance Index (CPI) [13]. Metode Composite Performance Index adalah metode yang didasarkan pada indeks kinerja gabungan dari berbagai alternatif terhadap kriteria yang tidak seragam [14]. Composite Performance Index (CPI) juga merupakan salah satu metode perhitungan pengambilan keputusan berbasis indeks gabungan kinerja yang dapat digunakan untuk menentukan peringkat atau rangking dari berbagai alternatif berdasarkan beberapa kriteria, walaupun kriterianya berbeda-beda [15]. Composite Performance Index (CPI) adalah metode yang umum digunakan dalam proses pengambilan keputusan) [16].

\section{Metode}

Dalam penyeleksian siswa baru dengan menggunakan metode Composite Performance Index (CPI) diperlukan kreteria-kreteria dan bobot untuk melakukan perhitungannya sehingga akan didapat alternative terbaik, dalam hal ini alternatif yang dimaksud adalah Peserta didik yang diterima. Kebutuhan informasi merupakan kebutuhan yang ada pada sistem dan informasi yang dihasilkan oleh sistem. Kebutuhan informasi pada sistem pendukung keputusan yang diusulkan adalah:

1. Kriteria yang dibutuhkan

Kriteria yang dibutuhkan untuk yang telah ditentukan adalah Kecerdasan kelakuan, kerapian dan kerajinan.

2. Bobot dan Tren

Bobot adalah prosentase nilai dari kriteria yang akan diambil. Total bobot kriteria bila ditambahkan tidak lebih dari satu.

Tabel 1. Bobot dan Tren Kriteria

\begin{tabular}{llll}
\hline NO & Kriteria & Bobot & Tren \\
\hline 1 & Kecerdasan & 0.4 & + \\
2 & Kelakuan & 0.1 & - \\
3 & Kerapian & 0.2 & - \\
4 & Kerajinan & $\underline{0.3}$ & + \\
\hline
\end{tabular}

Program ini dijalankan dengan mengunakan perangkat keras (Hardware) yang direkomendasikan sebagai berikut ini:

1. $\quad$ Prosecor Intel pentium dual-core $2.4 \mathrm{Ghz}$ atau yang lebih tinggi. 


\section{Suci Ananda Tarigan}

doi.org/10.54209/jatilima. V3i1.147

2. Memori Minimal $512 \mathrm{MB}$.

3. Harddisk $160 \mathrm{~GB}$ dengan freespace $500 \mathrm{MB}$ atau yang lebih tinggi.

4. VGA Card $64 \mathrm{MB}$ atau yang lebih tinggi.

5. Keyboard dan Mouse

Adapun perangkat lunak (Software) yang direkomendasikan untuk menjalankan aplikasi ini adalah sebagai berikut:

1. $M y S Q L$

2. $\quad$ Microsoft Visual Basic Net. 2008

\section{Hasil dan Pembahasan}

Tahap implementasi sistem merupakan proses yang dilakukan setelah tahapan perancangan sistem selesai dilaksanakan. Tujuan yang dicapai pada tahap ini adalah dapat dioperasikanya hasil perancangan sistem yang telah dibuat.

Pada perancangan aplikasi sistem pendukung keputusan penenutan ketua OSIS Smp Swasta Kavri Talun kenas ini menggunakan Visual Basic 2008 dengan menggunakan database mysql. Proses perancangan sistem aplikasi ini menggunakan UML (Unified Modeling Language) sebagai sebagai pemodelan sistem.

Ada beberapa diagram yang digunakan untuk memperjelas proses perancangan sistem aplikasi ini yaitu dengan mengimplementasikan penggunaan use case diagram dan activity diagram yang terdiri dari diagram activity siswa dalam membantu pembuatan perancangan sistem aplikasi ini.

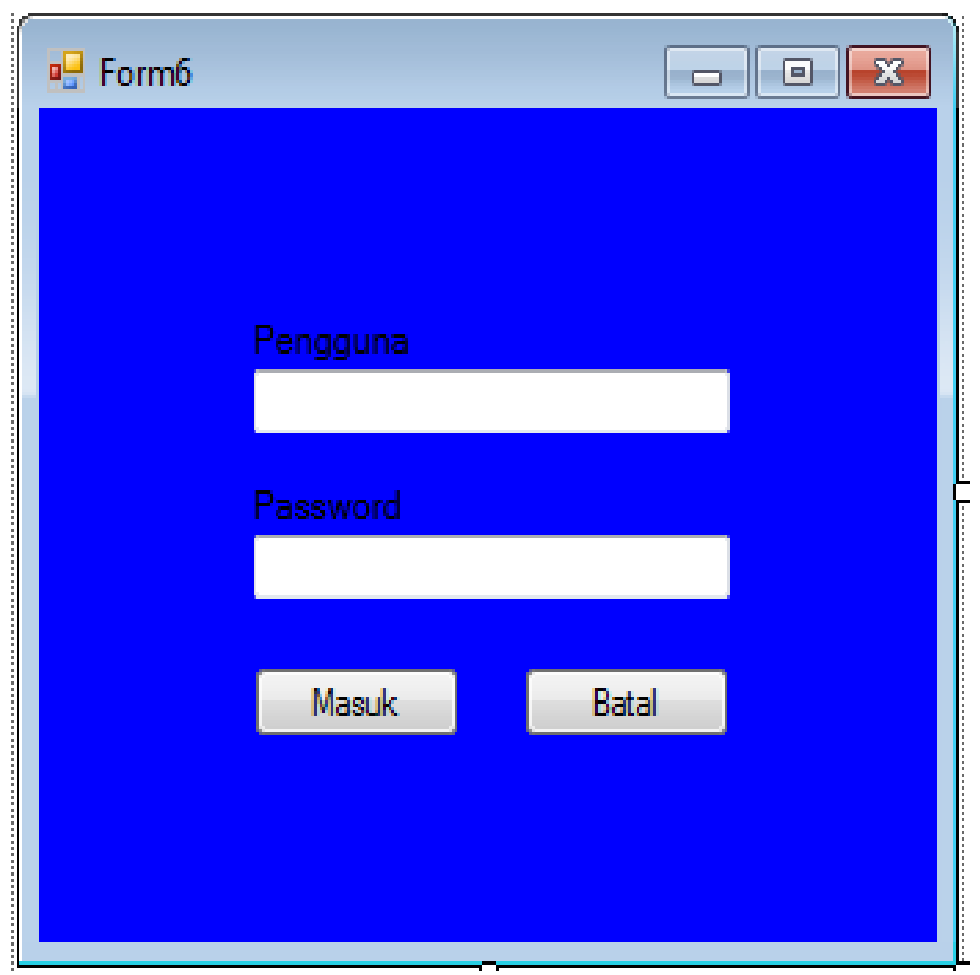

Gambar 1. Form Menu Login 
Pada form login ini pengguna diminta untuk menginputkan user name dan password agar dapat masuk ke form menu. Saat pertama kali aplikasi Penerimaan Siswa Baru dijalankan, maka akan tampil Form Login yang merupakan menu login bagi user biasa maupun bagi admin. Apabila pengguna sistem sebagai pengguna, cukup hanya dengan memilih pilihan user lalu pilih login, maka sistem akan berlanjut ke tampilan menu utama.

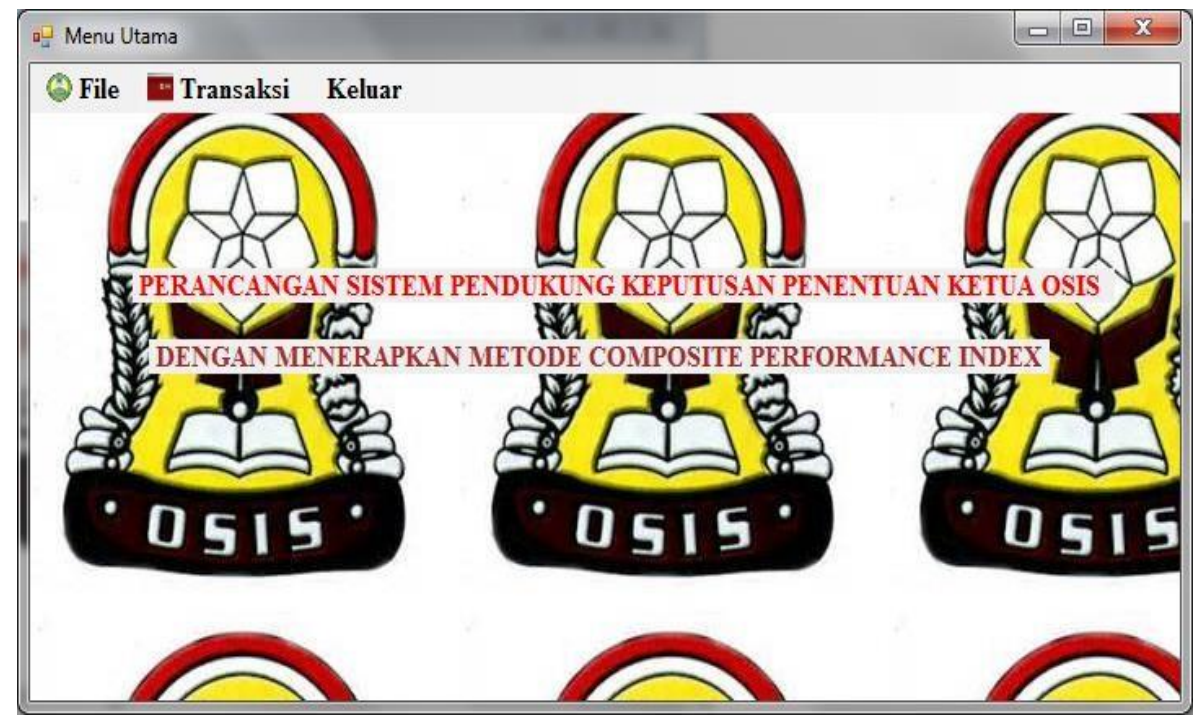

Gambar 2. Form Menu Utama

Tampilan menu utama digunakan untuk menampung semua pilihan-pilihan menu dan sub menu dalam sistem seperti menu user, menu pemakai, menu keterangan.

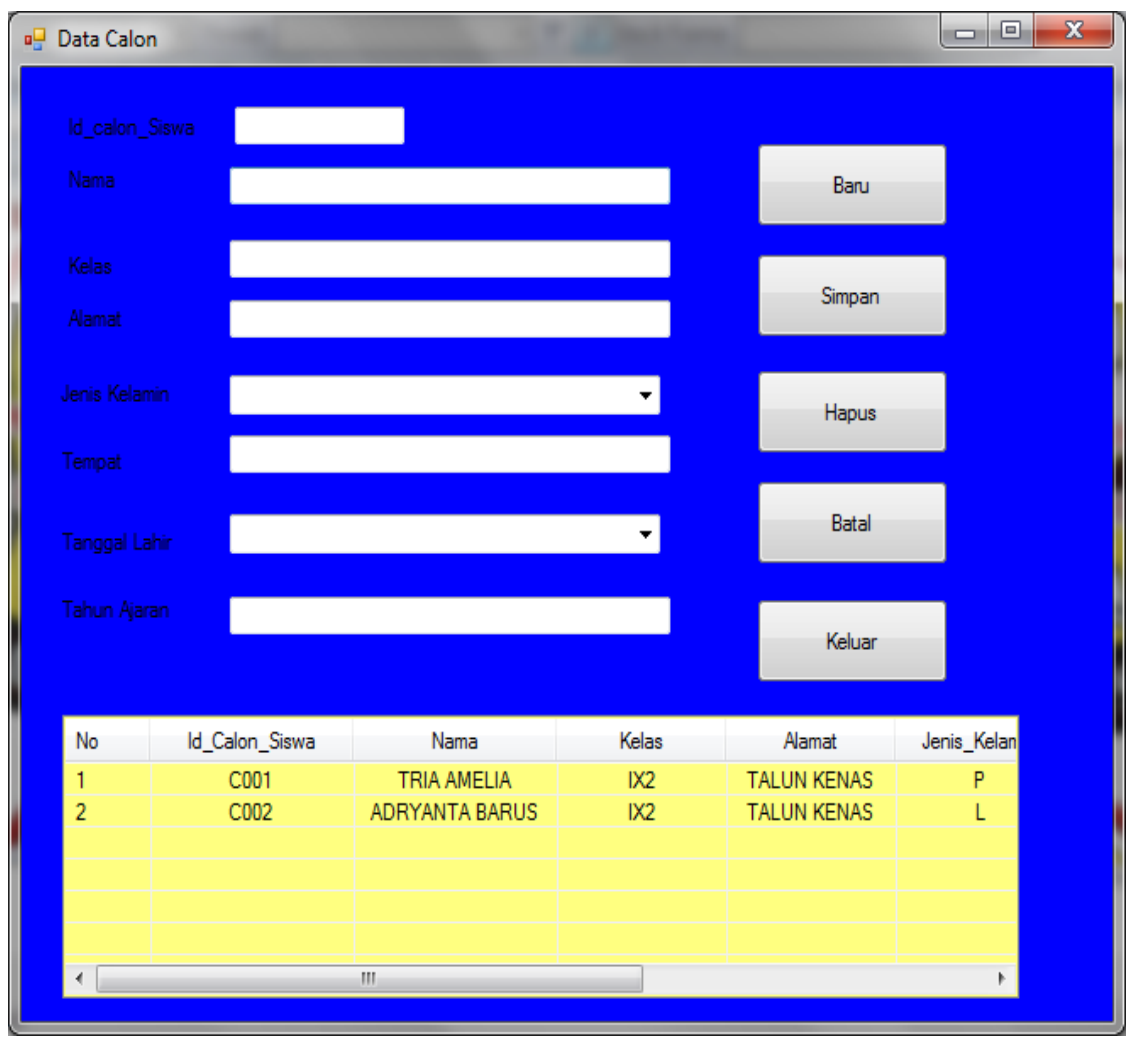

Gambar 3. Form Data Calon 


\section{Suci Ananda Tarigan}

doi.org/10.54209/jatilima. V3i1.147

Pada tampilan form input data Calon adalah untuk memasukkan data-data Siswa.

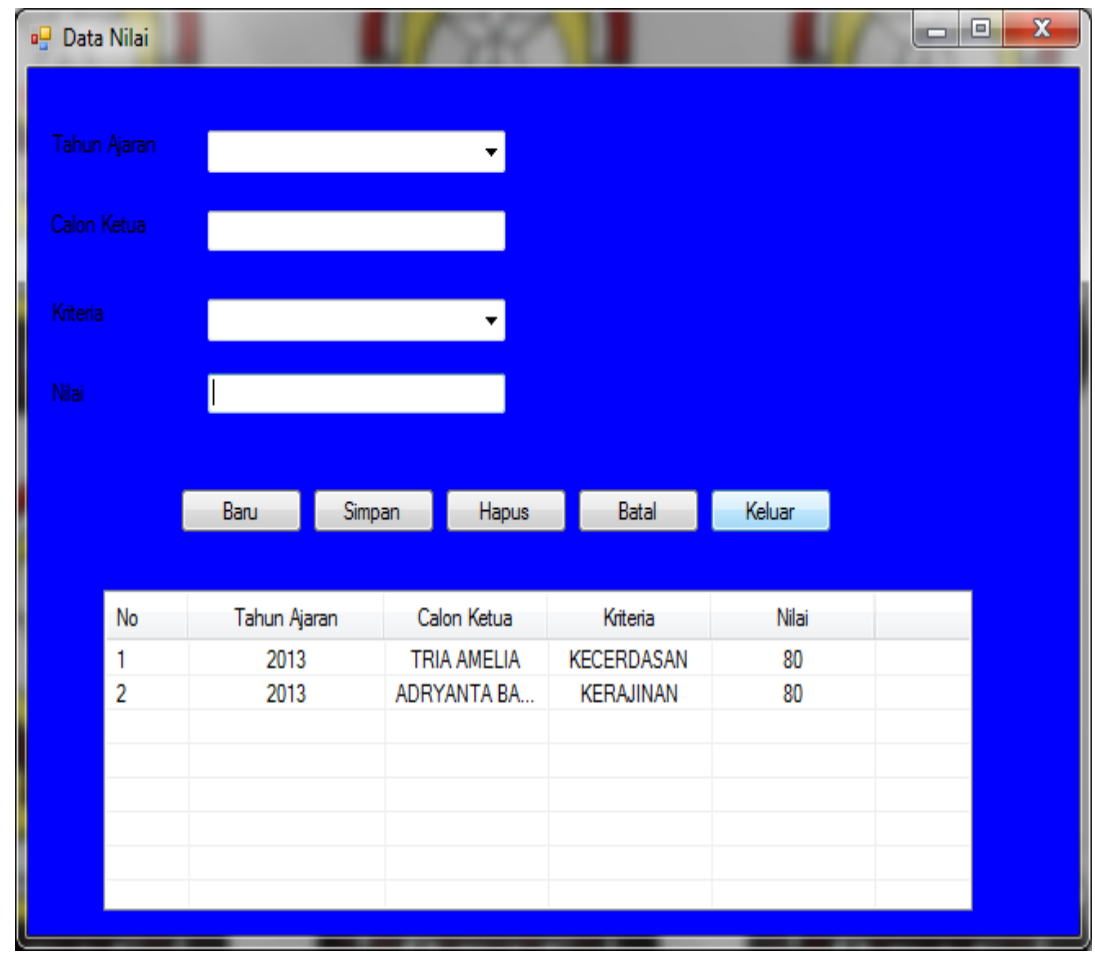

Gambar 4. Form Data Nilai

Menu ini digunakan untuk melakukan proses penentuan berdasarkan data Nilai yang dimiliki oleh Siswa.

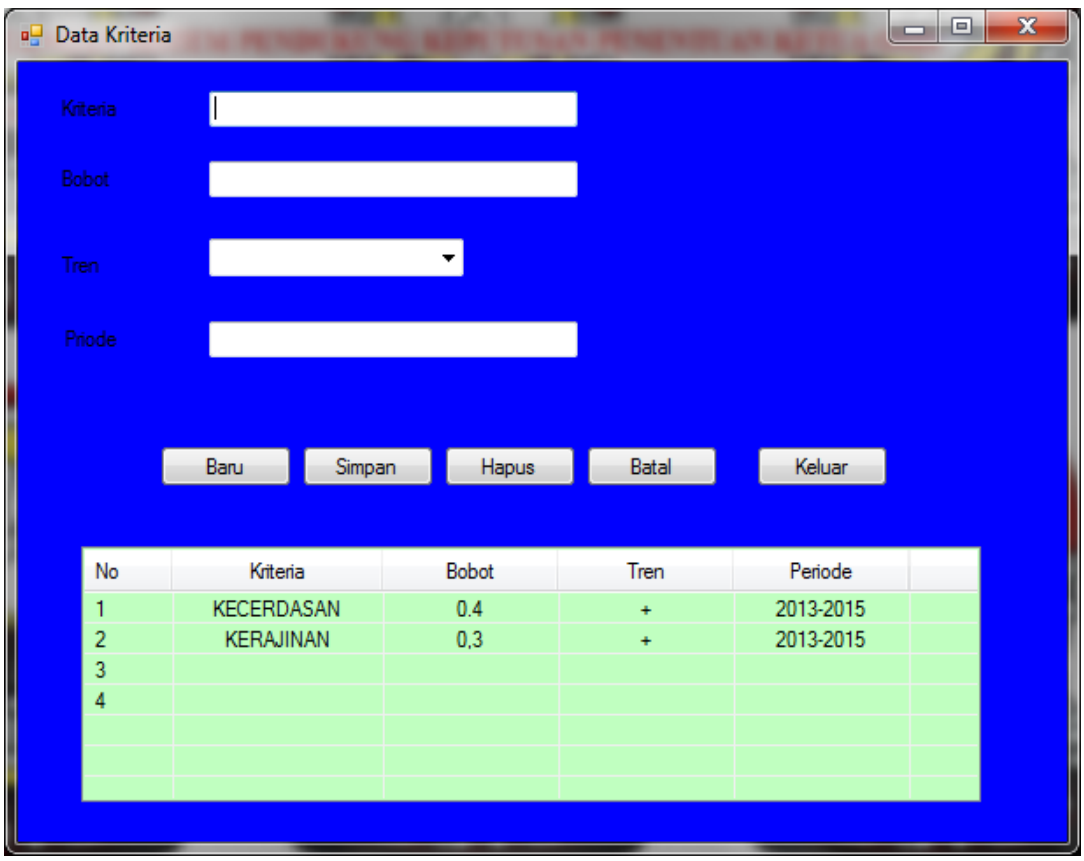

Gambar 5. Form Data Kriteria 
Menu ini digunakan untuk melakukan proses penentuan berdasarkan data Kriteria yang dimiliki oleh Siswa.

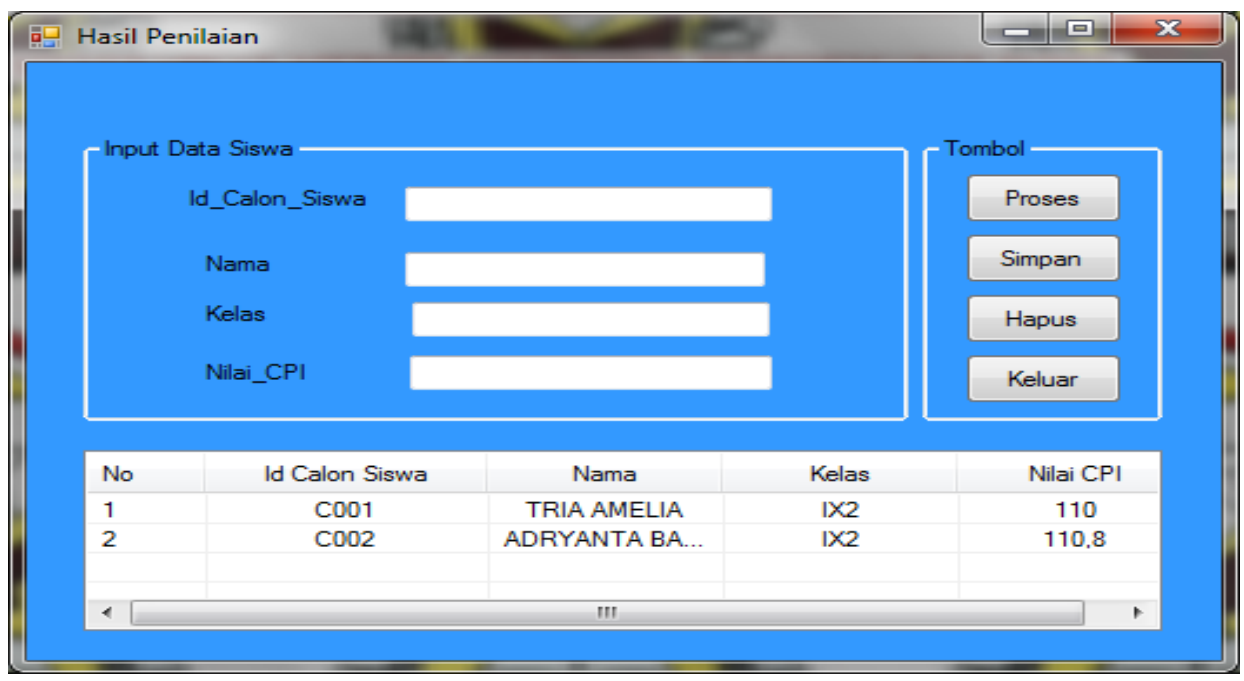

Gambar 6. Form Data Hasil Penilaian

Menu ini digunakan untuk melakukan proses hasil penentuan berdasarkan data Penilaian yang dimiliki oleh Siswa.

\section{Kesimpulan}

Dari hasil yang telah diperoleh penulis tentang penentuan ketua OSIS pada Smp Swasta Kavri Talun kenas, maka penulis dapat mengambil beberapa kesimpulan sebagai berikut: Sistem Penentuan Ketua OSIS yang sedang berjalan pada Smp Swasta kavri Talun kenas adalah memiliki Kriteria seperti kecerdasan kelakuan, kerajinan dan kerapian. Untuk mempermudah dan mempercepat proses penentuan ketua OSIS pada Smp Swasta Kavri Talun kenas dengan membuat perancangan aplikasi visual Basic 2008. Dengan menerapkan metode Composite Performance Index (CPI) pada Smp Swasta kavri dapat mempermudah Penentuan ketua OSIS. Sistem pendukung keputusan dapat dilakukan menentukan ketua OSIS pada Smp Swasta Kavri Talun Kenas lebih Objektif.

\section{Reference}

[1] M. Zainuddin, A. Syamsuadi, and M. R. Yahya, "PENINGKATAN EKSISTENSI ORGANISASI SISWA INTRA SEKOLAH (OSIS) SE KOTA PEKANBARU MELALUI KONSEP MANAJEMEN DAN KEPEMIMPINAN," J. Pengabdi. Masy. Multidisiplin, vol. 1, no. 2, 2018.

[2] S. H. Rangkuti, K. Simatupang, C. Situmeang, H. Pakpahan, and M. D. Barubara, "Aplikasi Pemilihan Ketua OSIS dengan Metode SMART(Simple Multi Attribute Rating Technique) Berbasis Android," J. Mantik Penusa, vol. 3, no. 1, 2019.

[3] Y. Ikhwani, "ANALISIS DAN RANCANGAN SISTEM E-VOTING PEMILIHAN KETUA OSIS,” Technol. J. Ilm., vol. 9, no. 3, 2018.

[4] F. A. Syam, Y. Darmayunata, and A. Afriansyah, "Perancangan Sistem E-Voting Untuk Pemilihan Ketua OSIS SMP Negeri 10 Pekanbaru," Zo. J. Sist. Inf., vol. 1, no. 2, 2020 . 


\section{Suci Ananda Tarigan}

doi.org/10.54209/jatilima. V3i1.147

[5] Z. Hisyam, M. Suyanto, and H. Al Fatta, "Analisa Perbandingan Metode Profile Matching Dan Topsis Dalam Pemilihan Ketua OSIS,” J. Inf. J. Penelit. dan Pengabdi. Masy., vol. 6, no. 1, 2020.

[6] Sriani and R. A. Putri, "Analisa Sistem Pendukung Keputusan Menggunakan Metode Topsis Untuk Sistem Penerimaan Pegawai Pada Sma Al Washliyah Tanjung Morawa," J. Ilmu Komput. dan Inform., vol. 02, no. April, 2018.

[7] F. I.-R. P. Computer, "Sistem Pendukung Keputusan Penerimaan Jurnalis Menerapkan MultiObjective Optimization On The Basis Of Ratio Analysis (MOORA)," JURIKOM (Jurnal Ris. Komputer), vol. 5, no. 1, 2018.

[8] S. W. Sari and B. Purba, "Sistem Pendukung Keputusan Pemilihan Ketua Danru Terbaik Menggunakan Metode ARAS," Semin. Nas. Teknol. Komput. Sains SAINTEKS 2019, 2019.

[9] Y. Zai, Mesran, and E. Buulolo, "Sistem Pendukung Keputusan untuk Menentukan Buah Rambutan Dengan Kualitas Terbaik Menggunakan Metode Weighted Product (WP)," Media Inform. Budidarma, vol. 1, no. 1, 2017.

[10] M. R. Noviansyah, W. Suharso, D. R. Chandranegara, M. S. Azmi, and M. Hermawan, "Sistem Pendukung Keputusan Pemilihan Laptop Pada E-Commerce Menggunakan Metode Weighted Product," Pros. SENTRA (Seminar Teknol. dan Rekayasa), vol. 0, no. 5, 2019.

[11] "Sistem Pendukung Keputusan Pemilihan Calon Ketua OSIS Menggunakan Metode SAW Pada SMA Negeri 3 Sigi Berbasis Website," e-Jurnal JUSITI (Jurnal Sist. Inf. dan Teknol. Informasi), vol. 9, no. 2, 2020.

[12] Yuli Fatimah, Aris Riswandi Sanusi, and Yogi Nugraha, "Solusi penanaman nilai-nilai Pancasila dalam kegiatan organisasi siswa intra sekolah (OSIS) di SMPN 4 Klari," Civ. J. Pendidik. Pancasila dan Kewarganegaraan, vol. 5, no. 1, 2020.

[13] A. A. Tri Susilo and M. Putri, "Sistem Pendukung Keputusan Pemberian Reward Kepada Karyawan Bandar Udara Silampari Lubuklinggau Menggunakan Metode Composite Performance Index(CPI)," J. Komput. Terap., vol. 2, no. 2, 2016.

[14] L. Sarumaha, B. Efori, A. H. Sihite, and D. P. Utomo, "Sistem Pendukung Keputusan Penempatan Mentor Pada Pusat Pengembangan Anak IO 558 Sangkakala Medan Menggunakan Metode CPI dan ROC," KOMIK (Konferensi Nas. Teknol. Inf. dan Komputer), vol. 4, no. 1, 2020.

[15] A. Nugroho and N. Bahtiar, "SISTEM PENDUKUNG KEPUTUSAN PENENTUAN NILAI KENAIKAN PANGKAT TNI ANGKATAN DARAT MENGGUNAKAN METODE COMPOSITE PERFORMANCE INDEX (CPI)," MATEMATIKA, vol. 19, no. 3, 2016.

[16] A. A. T. Susilo, "Penerapan Metode CPI Pada Pemilihan Hotel Dikota Lubuklinggau," J. RESTI, vol. 1, 2017. 